\title{
Nutrient-rich Whole Wheat Flour Supplement
}

National Cancer Institute

\section{Source}

National Cancer Institute. Nutrient-rich Whole Wheat Flour Supplement. NCI Thesaurus.

Code $C 124050$.

A nutritional supplement composed of nutrient-rich whole wheat flour-based bread mix, with potential anti-cachexia activity. Following the production of an unleavened bread from the mix and upon oral intake of the nutrient-rich whole wheat flour supplement, the various nutrients in the bread may improve cachexia symptoms. The bread is made from the flour of pulverized whole wheat from an Indian crop. 